\title{
LANDSLIDE HAZARD ZONATION MAPPING OF CHAMOLI LANDSLIDES IN REMOTE SENSING AND GIS ENVIRONMENT
}

\author{
Mahesh Kumar Tripathi ${ }^{*}$, Himanshu Govil ${ }^{1}$, P.K.Champati ray ${ }^{2}$, I.C. Das ${ }^{2}$ \\ ${ }^{1}$ National Institute of Technology Raipur (C.G.), India \\ ${ }^{2}$ Indian Institute of Remote Sensing, Dehradun \\ *Email-tripathi.mahesh1@gmail.com
}

KEYWORDS: Landslides, Chamoli, Remote Sensing, Hazard, Himalaya.

\begin{abstract}
:
Landslides are very common problem in hilly terrain. Chamoli region of Himalaya is highest sensitive zone of the landslide hazards. The purpose of Chamoli landslide study, to observe the important terrain factors and parameters responsible for landslide initiation. Lithological, geomorphological, slope, aspect, landslide, drainage density and lineament density map generated in remote sensing and GIS environment. Data information of related geological terrain obtain through topographic maps, remote sensing images, field visits and geological maps. Geodatabases of all thematic layers prepared through digitization of topographic map and satellite imageries (LISS-III, LISS-IV \& ASTER DEM). Integrated all thematic layers applying information value method under GIS environment to map the zonation of landslide hazard zonation map validation and verification completed by field visit. The landslide hazard zonation map classified in four classes very high, high, medium and low.
\end{abstract}

\section{INTRODUCTION}

A large part of Himalaya is affected by landslides. Each year in monsoon period, several landslides incidences are happened and published in newspaper in so many parts of Rishikesh- Badrinath National highway 58, Uttarakhand, India. Remote sensing techniques have a vital and significant role in landslide and mapping. Occurrences of landslide in a particular time and place with potential damages are a case sensitive phenomenon (Verns, 1984). Prediction of landslide susceptibility of an area largely depends on spatio-temporal occurrence of landslides. The studies of landslide hazard start with creation of landslide catalogue with respect to time and space (Isben and Brundsen, 1996). Characterization of landslides requires three-dimension perspectives which are possible by satellite images. There are various ways to map the landslides using remote sensing data and GIS techniques (Soeters and. Westen, 1996), and geomorphologic field mapping (Brunsden, 1999). Urban development and planning and implementation of infrastructure the LHZ maps have a vital role in hilly region (Anabalagan, 1992). Landslide is the result of variation in geological, geomorphologic and meteorological processes and factors. The main cause and factors of occurrences and initiation of land sliding described by Varnes (1984) and Hutchinson (1995). Through landslide hazard zonation map can estimate the probability of landslide occurrences in an area with respect to time and place, temporally. According to Saha et.al (2002), generation and prediction of landslide hazard zonation map can analyze through GIS and spatial data very precisely.

\section{STUDY AREA}

The study area situated in the Chamoli district of Garhwal Himalaya. It is bounded by North $30^{\circ} 15^{`} 30$ to $30^{\circ} 31^{\prime} 00$ latitude and East $79^{\circ} 15^{\circ} 00$ to $79^{\circ} 33^{\circ} 00$ longitude covering parts of survey of India toposheet no.53N/7 , 10,11 . To establish GIS-based modeling in portion of Alaknanda river catchment is studied. There are deep gorges and rugged mountains cover the entire region. The maximum elevation is $4627 \mathrm{~m}$ and the minimum elevation is $836 \mathrm{~m}$, with respect to mean sea level.

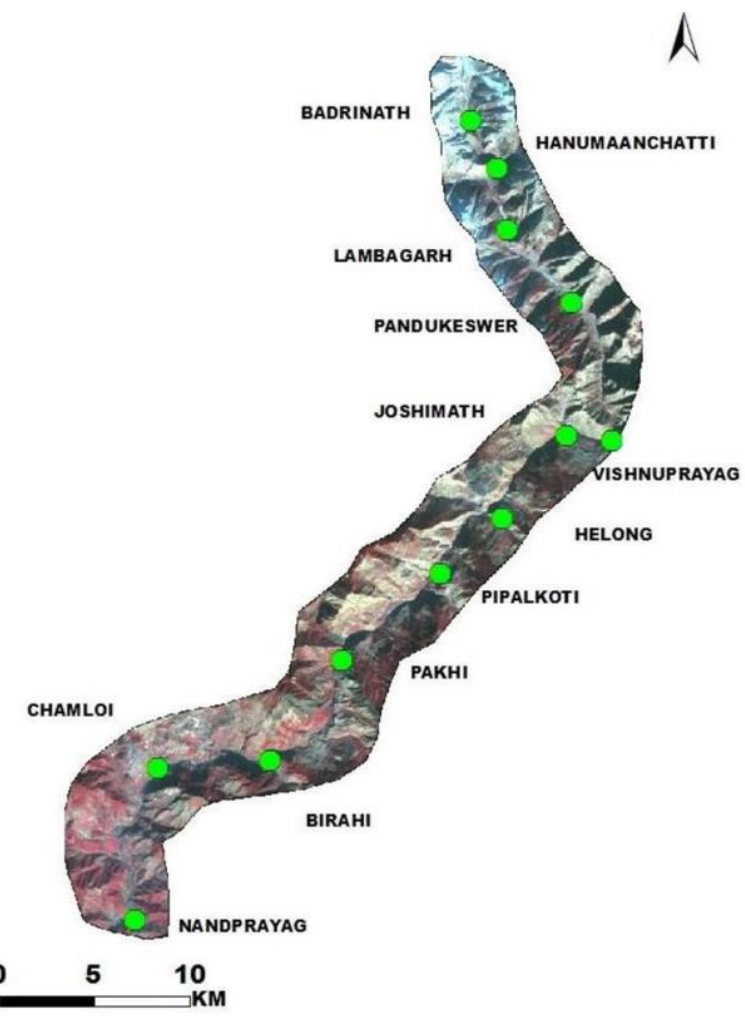

Figure 1. Location map of the study area.

3. METHODOLOGY 
A systematic methodological principle was adopted to study the work. There are two categories of whole work, in which preparation of all thematic layers in remote sensing and GIS environment through using ARCGIS and ERDAS software, after scanning and digitization of related data such SOI topographic maps and Remote Sensing data (IRS P6 LISS$3 / 4$ and ASTER DEM etc.). Main River was considered as single digitization. The classification of lineaments and faults depend on length. Prediction and generation of LHZ map, according to their relative importance, all thematic layers integrated in GIS environment (Kanungo et al. 2006).

\section{RESULT AND DISCUSSION}

There is various thematic GIS layer such as lithological, geomorphological, lineament, drainage, landslide, and structural, prepared for mapping of landslide hazard zonation under remote sensing and GIS environment. The initial or primary factors like as geology, drainage, anthropogenic activity, structure and climatic condition are responsible for instability in the study area. Generation of thematic data layers such as geomorphological, lithological, slope, aspect, lineament density, drainage density, landslide, NDVI map, information of layers based on geological, lithological, geomorphological, drainage, lineaments maps, remote sensing data and field survey of the study area.

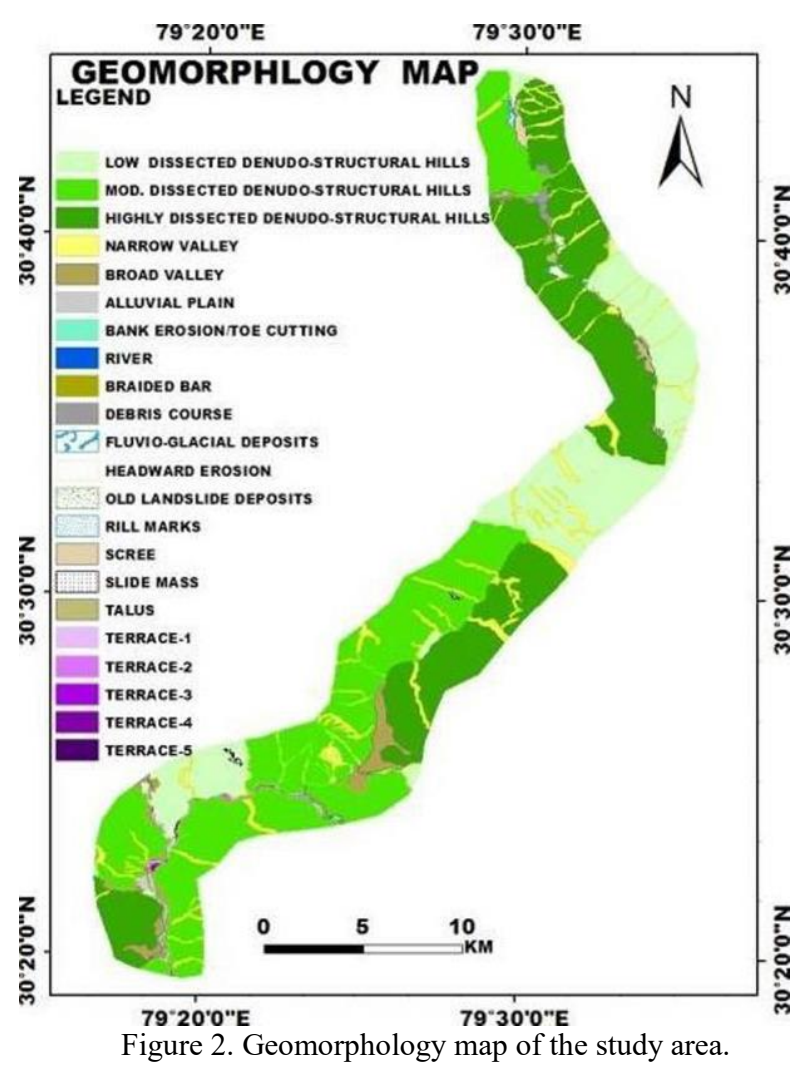

The study area is fully covered and associated with loose sediments on foot hills and river channels/ valleys, the cliffs, slopes in rocks waterfalls, ridges. Occurrences and initiation of landslides, lithology, lineaments, drainage are verified through satellite imageries and validated with field survey. The geomorphological map (figure.2) prepared under remote sensing and GIS platform with field validation. The lithological map (figure. 3) prepared by remote sensing image and validated with published geological map of Wadia Institute of Himalayan Geology (Thakur and Rawat, 1992), and satellite data and ground truth survey. Aspect and slope map (figure. $4 \& 5$ ) of the study area generated through using $30 \mathrm{~m}$ Aster DEM. There are seven classes (0$15,15-25,25-35,35-45,45-60$ and above 60 ) classified for determination of direction of slope in slope map classification (Dhakal, et al., 2000). Lineaments play a vital role in mass movement. Lineaments indicate zone of rupture and zones of weakness and also known as structural displacement as a geological discontinuity in the crust. Extraction of lineaments was completed by analogical and numerical analysis such as PCA, FCC, true color composite, edge enhancement, filtering, and field investigation by visual interpretation with help of image elements and terrain elements(van der Meer et al., 2012); (Allou and Bonin, 2015); (Alshayef et al., 2017); (Adiri et al., 2017).

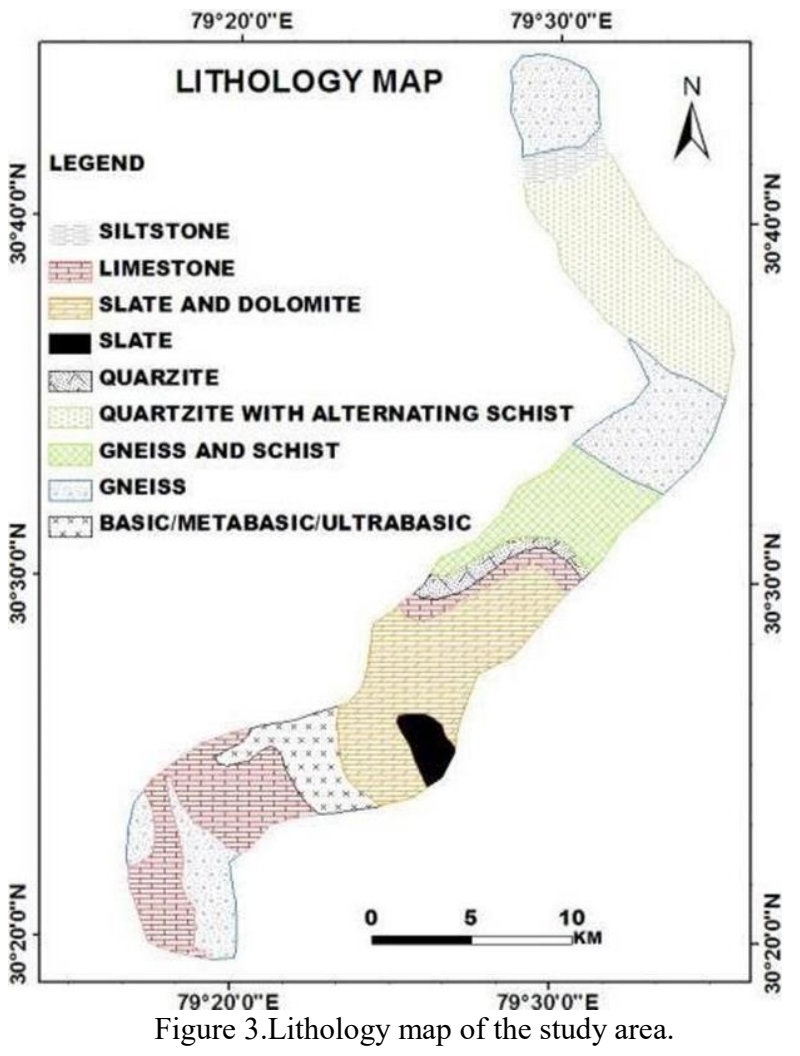


The calculation of density of lineament as per total length of lineaments per grid (Hashim et al., 2013); (Corgne et al., 2010); (Hung, Batelaan and Smedt, 2005) and classified on

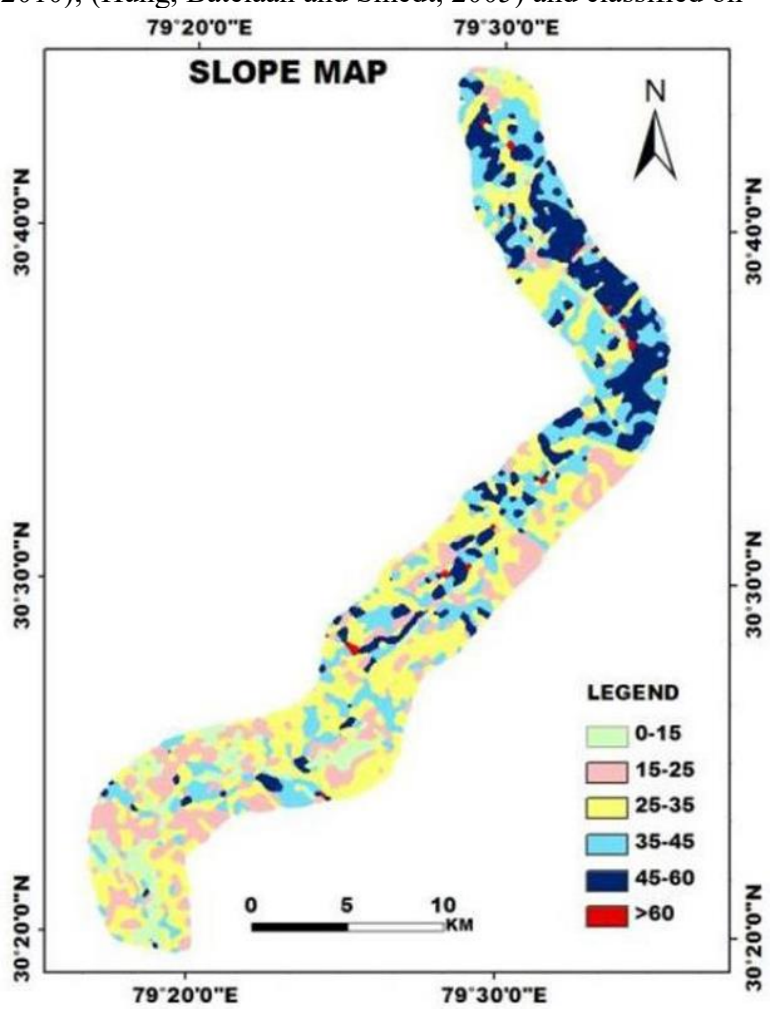

Figure 4.Slope map of the study area.

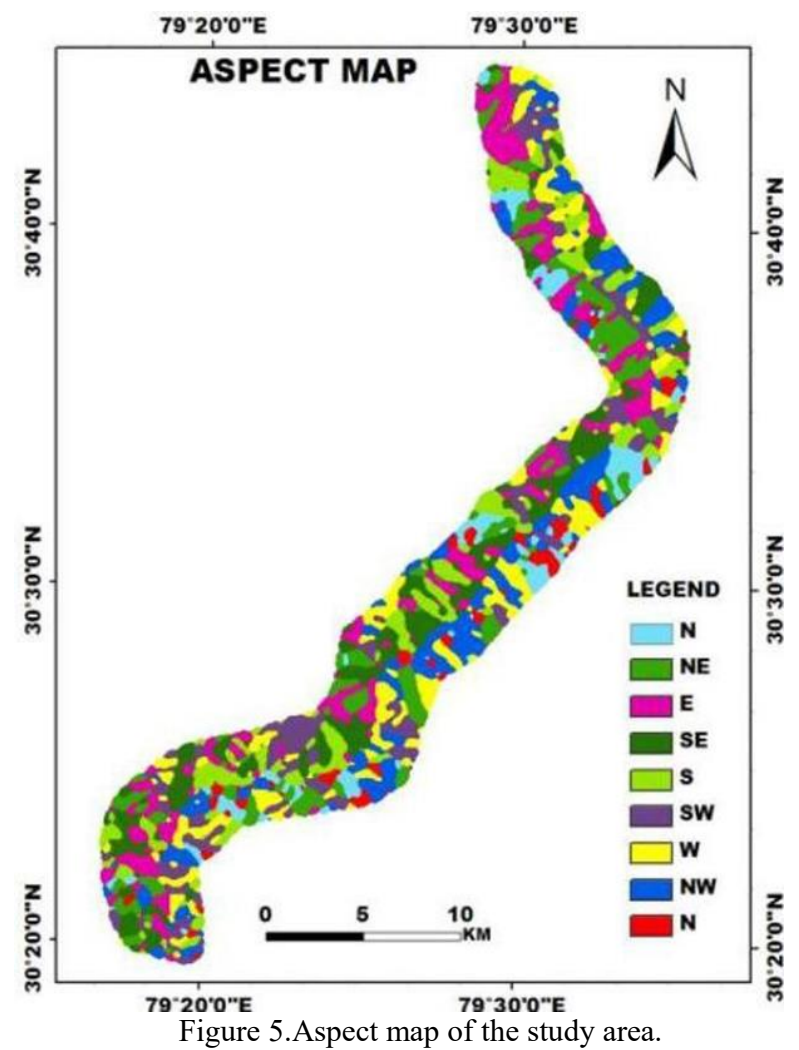

the basis of value of density into different class. The density values are ranging from 0 to 0.79 (figure.6). The drainage map prepared through remote sensing imagery and topographic maps though visual image interpretation using key elements of image and terrain. The dendritic pattern of main drainage is more prominent in the southern area which is parallel to sub-parallel in northern area. The calculated drainage density of study area ranging from 0 to 8.35 are classified in several classes which is shown in figure (7). Analysis of vegetation distribution and pattern from space through satellite image a numerical indicator such normalized vegetation index (NDVI) method applied, which is ranging between -1 to +1 . The Normalized Difference Vegetation Index (NDVI) can be used for analyses of vegetation from space through satellite images. NDVI values vary between -1 and +1 . The green vegetation in the NDVI map figure (8) showing higher NDVI values which is greater than zero in the study area. There are 5 classes of NDVI map in the study area on the basis vegetation density. Applying analogical and numerical analysis method for landslide mapping was prepared by high to moderate resolution satellite image with help of visual interpretation. This map is classified into two classes on the basis of slide area and non-slide area with ranging value was from $0-1$ have shown in figure (9).

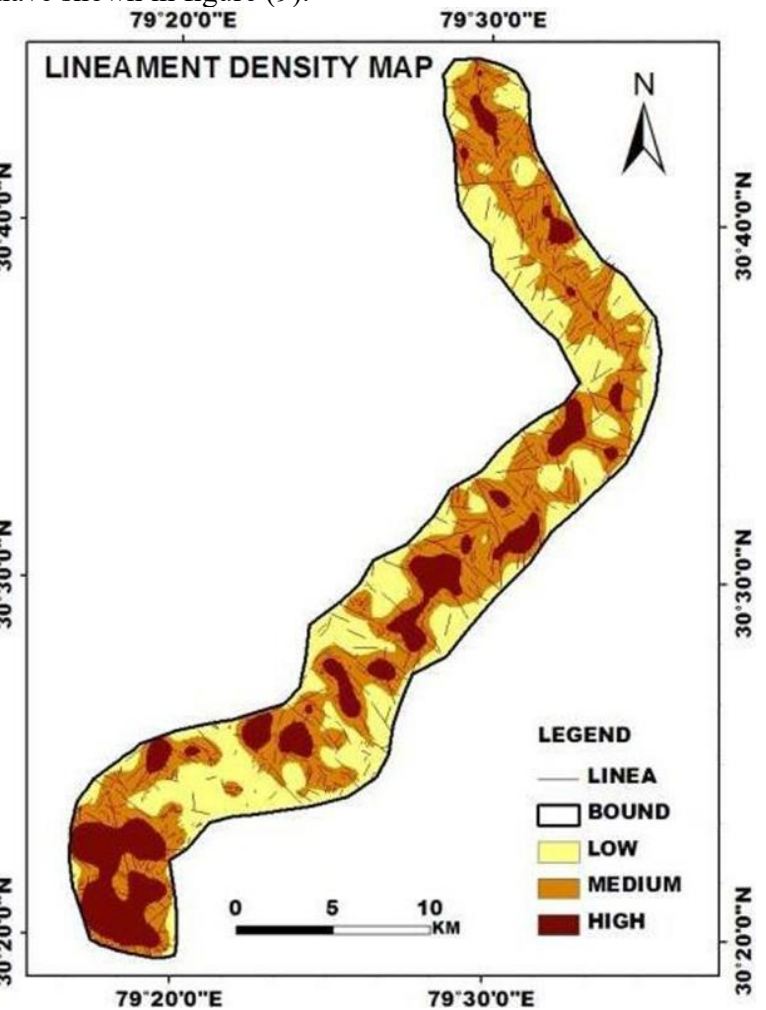

Figure 6. Lineament and lineament density map of the study area. 


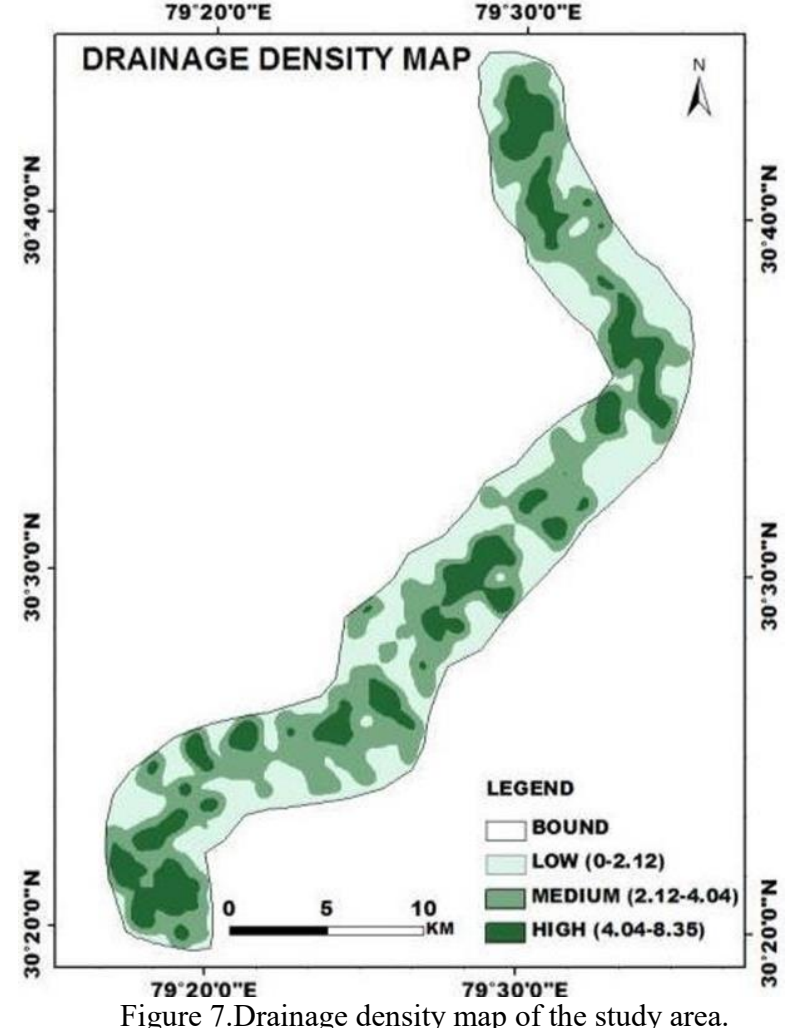

Figure 7.Drainage density map of the study area. 79'20'0"E

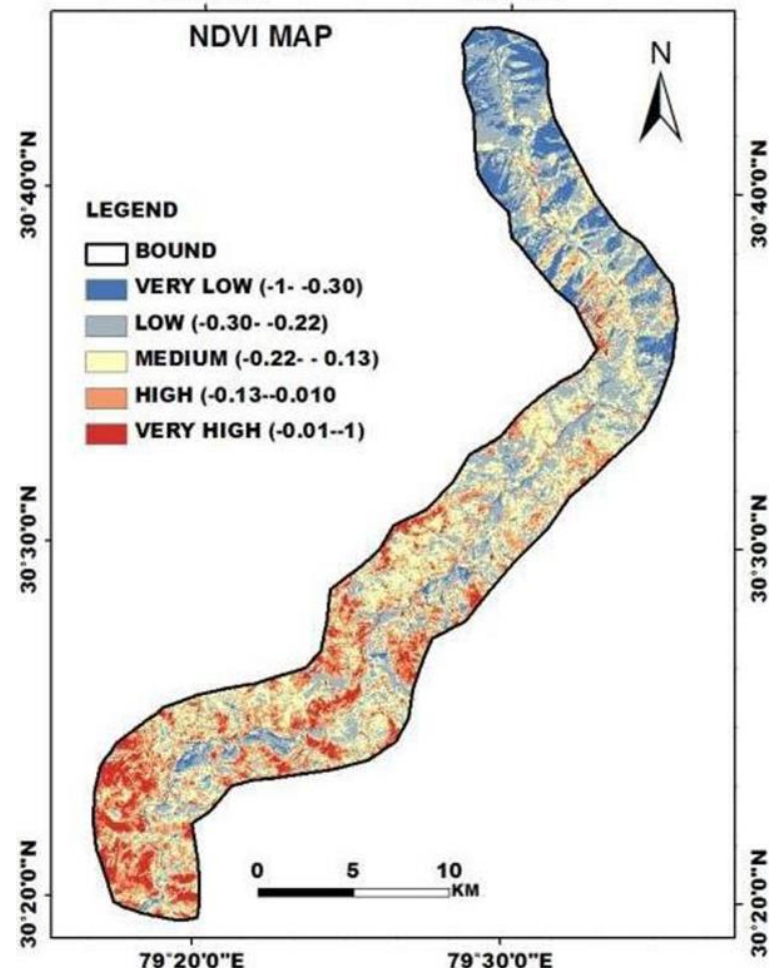

Figure 8. NDVI map of the study area

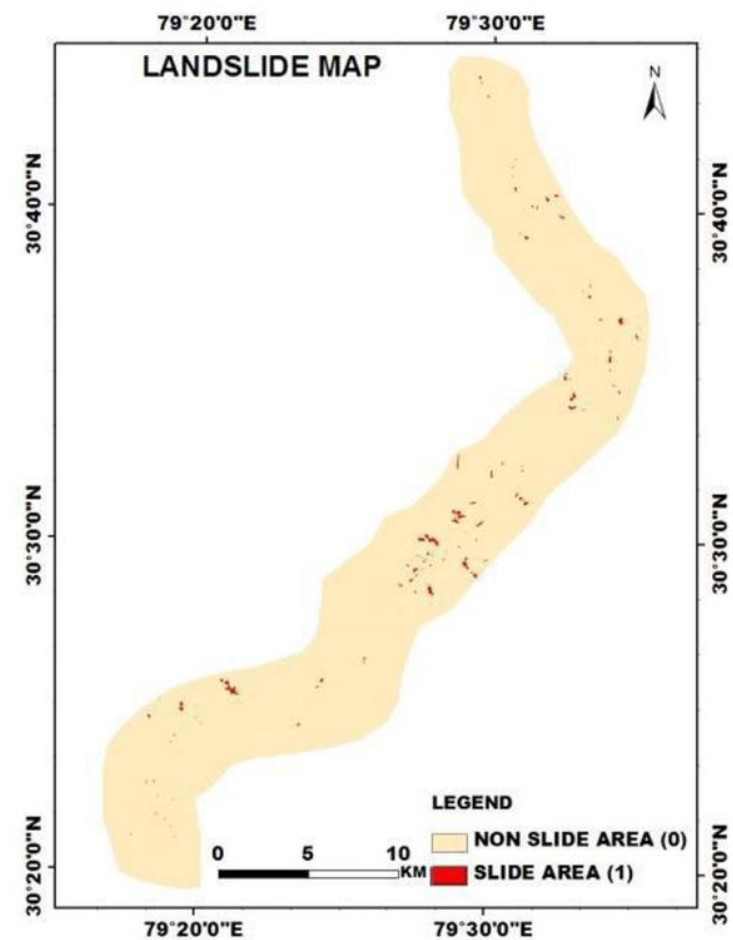

Figure 9. Landslide map of the study area.

LANDSLIDE HAZARD ZONATION MAPPING AND VALIDATION

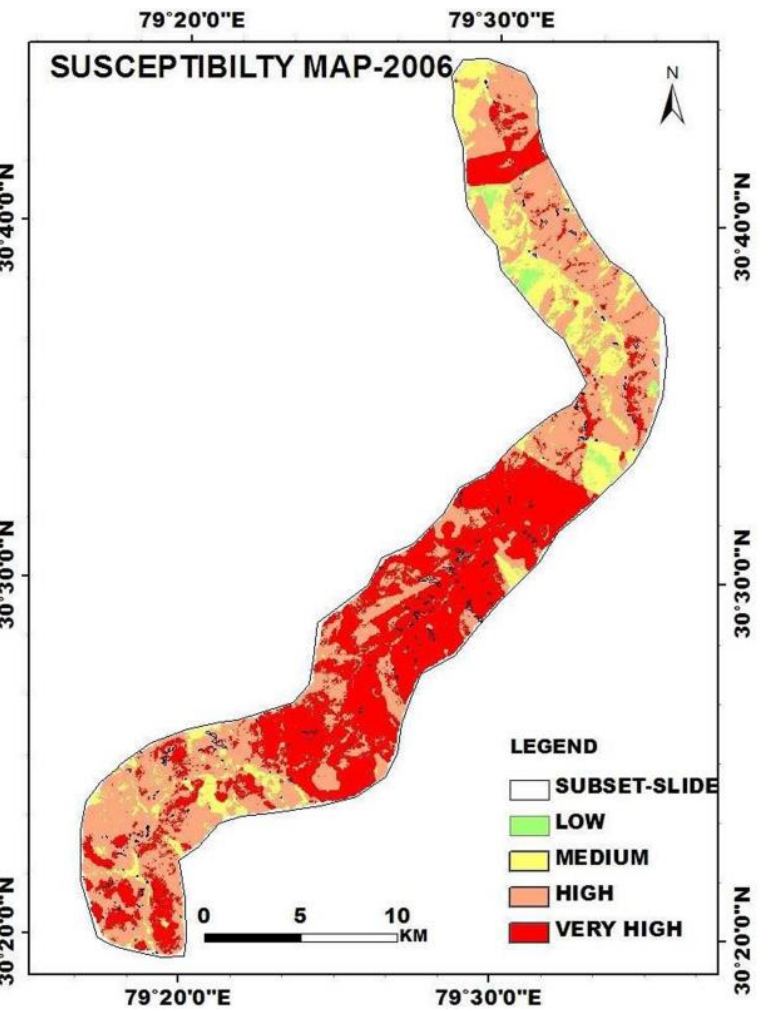

Figure 10.Landslide hazard zonation map of the study area. 


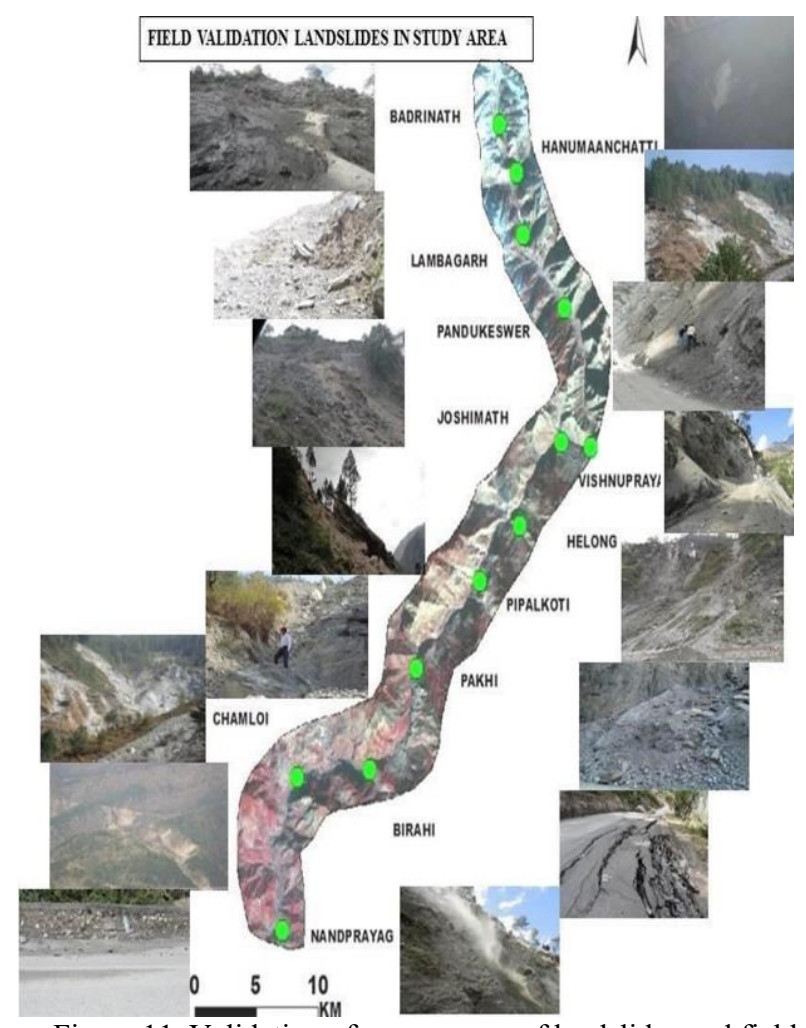

Figure 11. Validation of occurrences of landslides and field photographs.

Applying information value method in data layer integration for landslide hazard zonation mapping are classified into four category such as very high, high, medium, and low. The rank of each class of Landslide Hazard Zonation map is based on value of the category in different thematic layers. The very high category highly prone for landslide events, and low category is less prone for occurrences and initiation and of landslides in the study area.

\section{CONCLUSION}

The assessment and implementation of landslide hazard zonation mapping is under remote sensing and GIS environment is more significant for broad prospective. The adopted methodology and data completely implemented accurately in the study area. The advantage of assessment of landslide occurrences, initiation and potential along with landslide zonation map, topographic map, cadastral map, and potential and capability of remote sensing data in hilly and highly dissected terrain. The geological, geomorphological, lithological, and climatological information are applied to prepare landslide hazard zonation in digital format to monitor and assess landslides in the study.

\section{REFERENCES}

D. J. Varnes, Landslide Hazard Zonation: A Review of Principles and Practice, Natural Hazards 3, Commission on Landslides of the IAEG, UNESCO, Paris, 1984, 63p.

Isben, M.I., and Brundsen, D., 1996., Mudslide, in R.Diku et al (eds) Landslide Recognition, 103-119, Chichester; Wiley.

Soeters, R., and C.J.v .Westen, 1996, Slope Instability recognition, analysis, and zonation, in A. Turner, and $\mathrm{R}$. Schuster, eds., Landslides investigation and mitigation. Transportation Research Board Sp report 247, National Academy press, Washington, p. 129-177.

Brunsden, D., 1999, Some geomorphological considerations for the future development of landslide models. Geomorphology, v.30 p. 13-24.

R. Anabalagan, Landslide Hazard Evaluation and Zonation Mapping in Mountainous Terrain, Engineering Geology, Vol. 32, No. 4, 1992, pp. 269-277. http://dx.doi.org/10.1016/0013-7952 (92)90053-2.

N. Hutchinson, Keynote Paper: Landslide Hazard Assessment, In: Bell, Ed., Landslides, Balkema, Rotterdam, 1995, pp. 1805-1841.

Saha, R. P. Gupta and M. K. Arora, GIS-Based Landslide Hazard Zonation in the Bhagirathi (Ganga) Valley, Himalayas, II International Journal of Remote Sensing, Vol. 23, No. 2, 2002, pp. 357-369.

D. P. Kanungo, M. K. Arora, S. Sarkar and R. P. Gupta, Comparative Study of Conventional, ANN Black Box, Fuzzy and Combined Neural and Fuzzy Weighting Procedures for Landslide Susceptibility Zonation in Darjeeling Himalayas, ॥ Engineering Geology, Vol. 85, 2006, pp. 347-366.

V. C. Thakur and B. S. Rawat, Geological Map of the Western Himalaya, Wadia Institute of Himalayan Geology, Dehradun, 1992.

A.S. Dhakal, T. Amada and M. Aniya, Landslide Hazard Mapping and Its Evaluation Using GIS: An Investigation of Sampling Schemes for a Grid-Cell Based Quantitative Method, Photogrammetric Engineering \& Remote Sensing, Vol. 66, No. 8, 2000, pp. 981-989.

Adiri, Z. et al. (2017) 'Comparison of Landsat-8, ASTER and Sentinel 1 satellite remote sensing data in automatic lineaments extraction: A case study of Sidi Flah-Bouskour inlier, Moroccan Anti Atlas', Advances in Space Research. doi: 10.1016/j.asr.2017.09.006.

Allou, G. and Bonin, B. (2015) 'The Landsat 7 etm+ remote sensing imagery for lithological and structural mapping in Cote D Ivoire (West Africa): Case of Dabakal area.', 11(36), pp. 141-163.

Alshayef, M. S. et al. (2017) 'Manual and Automatic Extraction of Lineaments From Multispectral Image in Part of Al-Rawdah, Shabwah, Yemen by Using Remote Sensing and GIS Technology', (2), pp. 67-73. 
Corgne, S. et al. (2010) 'An integrated approach to hydrogeological lineament mapping of a semi-arid region of West Africa using Radarsat-1 and GIS.', REMOTE SENS. ENVIRON, 114, pp. 1863-1875.

Hashim et al. (2013) 'Automatic lineament extraction in a heavily vegetated region using Landsat Enhanced Thematic Mapper (ETM+) imagery', Adv. Space Research, 51, pp. 874-890.

Hung, L. ., Batelaan, O. F. and Smedt, F. (2005) 'Lineament Extraction and Analysis, Comparison of LANDSAT ETM and ASTER Imagery. Case study: Suoimuoi Tropical Karst Catchment, Vietnam.', Remote Sensing for Environmental Monitoring, GIS Applications, and Geology, 5983.

van der Meer, F. D. et al. (2012) 'Multi- and hyperspectral geologic remote sensing: A review', International Journal of Applied Earth Observation and Geoinformation. Elsevier sB.V., 14(1), pp. 112-128. doi: 10.1016/j.jag.2011.08.002. 